\title{
CRYSTAL HYDRATION AND VACANCY ENHANCED ISOTOPIC EXCHANGE REACTIONS IN HETEROGENEOUS SOLID - LIQUID SYSTEMS
}

\author{
By
}

T. BRAUN

Institute of Inorganic and Analytical Chemistry, L. Eötvös University, P.O. Box 123, 1443, Budapest Hungary
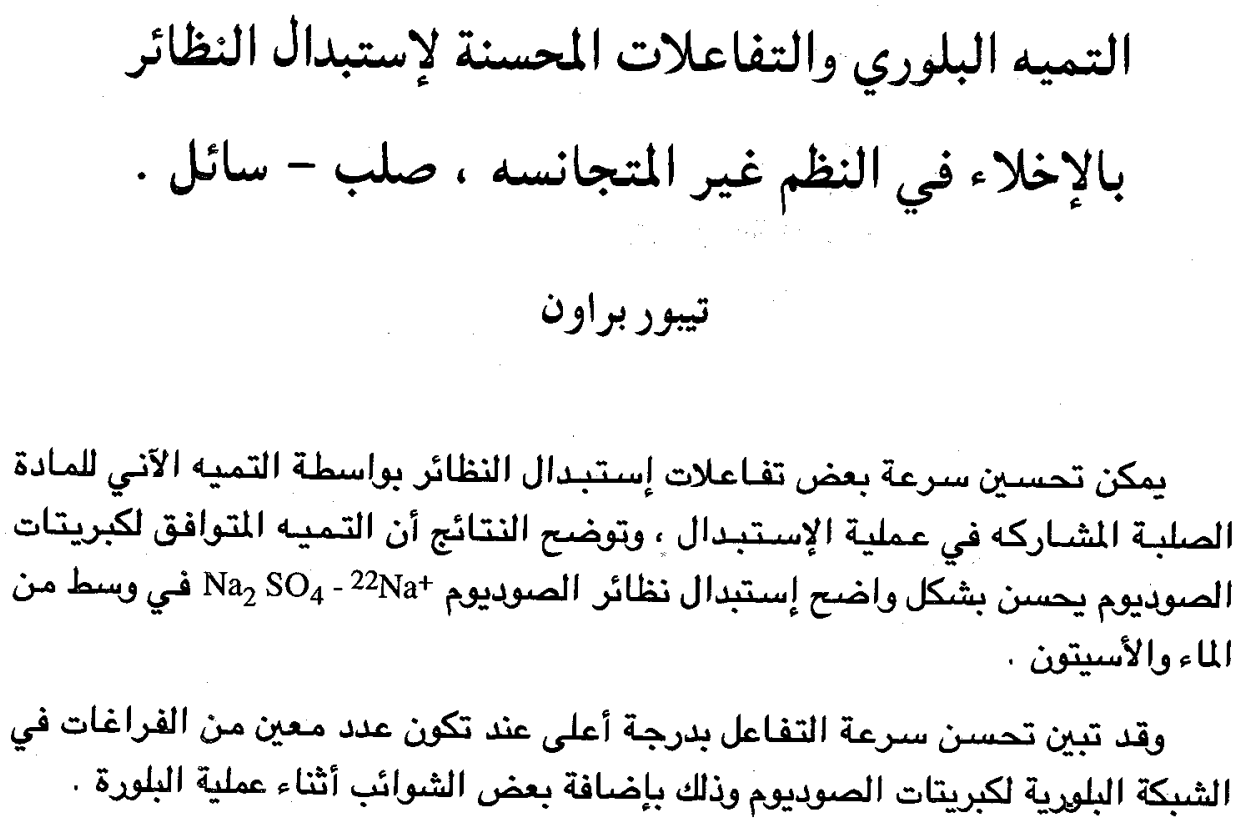

Key Words: Crystal hydration, Enhanced isotopic exchange, Heterogeneous solid-liquid systems.

\section{ABSTRACT}

The rate of some heterogeneous isotopic exchange reactions can be enhanced by the simultaneous hydration of the solid participating in the exchange process. The results presented here show that the concomitant hydration of anhydrous sodium sulphate enhances the $\mathrm{Na}_{2} \mathrm{SO}_{4}{ }^{-22} \mathrm{Na}^{+}$isotopic exchange reaction in a water - acetone medium. The reaction rate is further enhanced by creating a controlled number of vacancies in the crystal lattice of sodium sulphate by doping.

\section{INTRODUCTION}

It is known[1] that "for many solid-liquid heterogeneous isotopic exchange reactions there is an initial relatively rapid exchange between the reactant on the surface of the solid and the reactant in the liquid. This initial reaction is then followed by the relatively slow process of incorporation of surface material into the body of the lattice by self-diffusion and/or recrystallization. The extent of the initial rapid exchange is, of course, dependent on the amount of solid surface exposed and has been used in the estimation of the specific surface of solids. The rate of progress of the later phase of the exchange reaction is dependent on the solid particle size, the perfection of the crystal lattice, the temperature, the solubility of the solid in the liquid, and other factors that influence the rate of recrystallization of the solid and the mobility of the components of the solid. There are, however, other possible mechanisms for such reactions, e.g. our recent measurements showed that the concomitant hydration of anhydrous sodium sulphate in acetone-sodium sulphate saturated aqueous solution enhances the rate of the isotopic exchange reaction.

$$
\begin{gathered}
\left(\mathrm{Na}_{2} \mathrm{SO}_{4}\right)_{\text {solid }_{1}}+\left(2^{22} \mathrm{Na}^{+}\right)_{\text {liq. }}+\left(\mathrm{xH}_{2} \mathrm{O}\right)_{\text {liq. }} \rightleftharpoons \\
\left({ }^{22} \mathrm{Na}_{2} \mathrm{SO}_{4} \cdot \mathrm{xH}_{2} \mathrm{O}\right)_{\text {solid }_{2}}+\left(2 \mathrm{Na}^{+}\right)_{\text {liq. }} .
\end{gathered}
$$

In order to prove that the enhancement arises from the concomitant hydration of the anhydrous solid phase, the behavior of sodium sulphate decahydrate in the isotopic exchange reaction under exactly the same experimental conditions as has been studied.

$$
\begin{gathered}
\left(\mathrm{Na}_{2} \mathrm{SO}_{4} .10 \mathrm{H}_{2} \mathrm{O}\right)_{\text {Solid }_{1}}+\left(2^{22} \mathrm{Na}^{+}\right)_{\text {liq. }} \\
\left({ }^{22} \mathrm{Na}_{2} \mathrm{SO}_{4} .10 \mathrm{H}_{2} \mathrm{O}\right)_{\text {solid }_{2}}+\left(2 \mathrm{Na}^{+}\right) \text {liq. }
\end{gathered}
$$

\section{EXPERIMENTAL}

The experimental conditions are given in Table 1. The heterogeneous isotopic exchange was carried out in glass 
vessels with stirrers at a temperature of $20 \pm 2{ }^{\circ} \mathrm{C}$. Gamma ray measurements were made by a Hungarian energy selective counting equipment and a $\mathrm{NaI}$ (T1) well-type scintillator.
The purity of the $22 \mathrm{Na}$ isotope was checked by gamma spectrometry. The doped sodium sulphate samples were prepared by the previously described procedure[2].

Table 1

Experimental conditions for the isotopic exchange reaction

\begin{tabular}{|c|c|c|c|c|c|}
\hline Solid & Medium & & Weight of solid, $g$ & Particle size of solid, $\mathrm{mm}$ & Isotope \\
\hline $\mathrm{Na}_{2} \mathrm{SO}_{4}$ & $\begin{array}{l}\text { Sat. sol. of } \mathrm{Na}_{2} \mathrm{SO}_{4} \text { : } \\
\text { acetone }\end{array}$ & $\begin{array}{r}2 \mathrm{ml} \\
28 \mathrm{ml}\end{array}$ & 2.8 & $0.25-0.80$ & $22 \mathrm{Na}$ \\
\hline $\mathrm{Na}_{2} \mathrm{SO}_{4} .10 \mathrm{H}_{2} \mathrm{O}$ & $\begin{array}{l}\text { Sat. sol. of } \mathrm{Na}_{2} \mathrm{SO}_{4} \text { : } \\
\text { acetone }\end{array}$ & $\begin{array}{r}2 \mathrm{ml} \\
28 \mathrm{ml}\end{array}$ & 4.0 & $0.25-0.80$ & $22 \mathrm{Na}$ \\
\hline Doped $\mathrm{Na}_{2} \mathrm{SO}_{4}$ & $\begin{array}{l}\text { Sat. sol. of } \mathrm{Na}_{2} \mathrm{SO}_{4}: \\
\text { acetone }\end{array}$ & $\begin{array}{r}2 \mathrm{ml} \\
28 \mathrm{ml}\end{array}$ & 2.8 & $0.25-0.80$ & ${ }^{22} \mathrm{Na}$ \\
\hline
\end{tabular}

\section{RESULTS AND DISCUSSIONS}

Figure 1 shows some of the results. The rate curves on the figure are similar to those of independently decaying radioactivities, indicating the multi-step nature of the exchange reaction. In order to analyze the curve corresponding to the exchange with non-hydrated sodium sulphate (curve I) the final linear portion was extrapolated back to $t=0$, and on subtracting the extrapolated line from the original curve, another straight line is obtained which represents the rate of (Fig.1) the initial (enhanced) reaction (curve II). The overall exchange is thus seen to consist of a fast (enhanced) process followed by a relatively slower process which completes the $\mathrm{Na}_{2} \mathrm{SO}_{4}-22 \mathrm{Na}^{+}$exchange. It is, however, possible that there may be other contributing steps which are not resolved by this analysis. In the case of the exchange reaction with sodium sulphate decahydrate, curve III shows that the fast (enhanced) step is absent (or extremely short) and the exchange practically follows a one step slow mechanism.

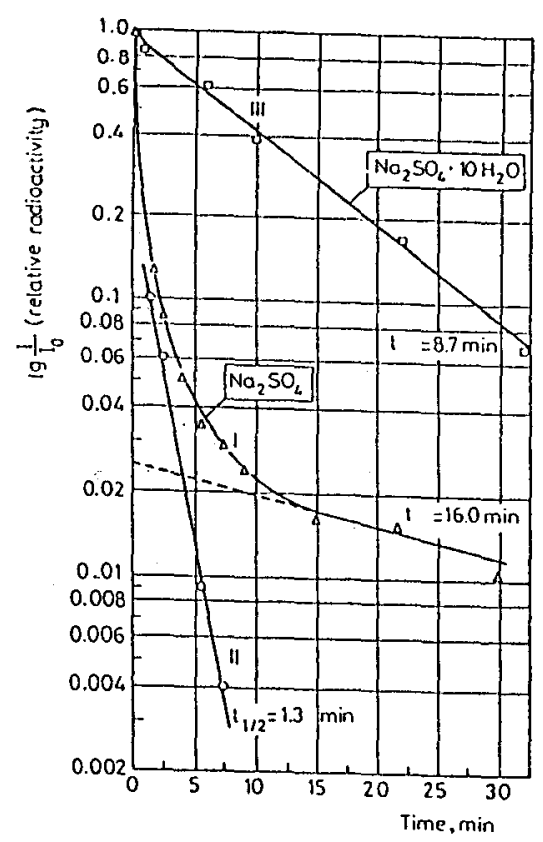

Fig. 1 Isotopic exchange reaction rates in the (solid) sodium sulphate (anhydrous and decahydrate) -sodium-22 system $\Delta$, o- $\mathrm{Na}_{2} \mathrm{SO}_{4} ; \square-\mathrm{Na}_{2} \mathrm{SO}_{4} .10$ $\mathrm{H}_{2} \mathrm{O} ; \mathrm{I}_{\mathrm{o}}$-radioactivity at time $=0(\mathrm{cpm}) ; \mathrm{I}_{\mathrm{t}^{-}}$ radioactivity at time $=\mathrm{t}(\mathrm{cpm})$
The experimental evidence indicates that the crystal hydration of anhydrous sodium sulphate enhances the surface exchange and bulk diffusion processes further during the isotopic exchange of sodium in the acetone-salt saturated water system. The enhancing effect seems not to be restricted to this system. Preliminary experiments indicated that the reactivity enhancement by hydration is of a pretty general nature applying to isotopic exchange reactions involving many crystal hydrates for which hydrationdehydration is reversible.

Although some implications of our findings and underlying mechanisms have yet to be assessed and understood, it seems probable that the hydration cluster surrounding the $\mathrm{Na}^{+}$ions in solution acts as an ion implanting vehicle for the ions to be exchanged during the hydration of the anhydrous salt, enhancing the overall rate of the isotopic exchange process. It is known that if there is a big difference in solvating power, then one solvent only may be found in the primary solvation shell, as in aqueous acetone[3]. At least one evidence for the inverse effect already exists, namely Lieser[4] reported that in the isotopic exchange reaction between solid $\mathrm{SrSO}_{4}$ and ${ }^{90} \mathrm{Sr}^{2+}$ in a water methanol system the ${ }^{90} \mathrm{Sr} 2+$ ions penetrating the surface of the crystals must at least partially strip off their hydration shell. In case of our hydration enhanced exchange mechanism the contrary happens, i.e. the cluster of hydrating water molecules carry and implant into the crystal the exchangeable radioactive ions from within the hydration shell.

Recent investigations by Eysel et al.[2] have shown that the defect structure of anhydrous sodium sulphate can controllably be modified by doping (replacement of $\mathrm{Na}$ ) by the aliovalent ions $\mathrm{M}^{2+}$ and $\mathrm{M}^{3+}$, which causes up to $30 \%$ vacancies $(\square)$ in the cation sublattice described by:

$$
\mathrm{Na} 2-2 \mathrm{M}_{\mathrm{X}}{ }^{2+} \square_{\mathrm{X}} \mathrm{SO}_{4} \text { and } \mathrm{Na} 2-3 \mathrm{x}_{4} \mathrm{M}^{3+} \square_{2 x} \mathrm{SO}_{4}
$$

Using the method described by Eysel et al.[2] we have prepared some batches of $\mathrm{Cu}^{2+}, \mathrm{Co}^{2+}$ and $\mathrm{Y}^{3+}$ doped sodium sulphate and did investigate the effect of vacancies on the rate of the heterogeneous sodium isotopic exchange between sodium sulphate and sodium ions in water-acetone solutions. The results are presented in Table 2. 
Table 2

Rate of isotopic exchange of sodium -22 on sodium sulphated decahydrate and on undoped anhydrous sodium sulphate

\begin{tabular}{lcc}
\hline Solid & \multicolumn{2}{c}{ Retention half-times, min } \\
& 1.Step* & 2. Step \\
\hline $\mathrm{Na}_{2} \mathrm{SO}_{4} \cdot 10 \mathrm{H}_{2} \mathrm{O}$ & - & 8.70 \\
$\mathrm{Na}_{2} \mathrm{SO}_{4}$ & 1.30 & 16.00 \\
$\mathrm{Na}_{1} .80 \mathrm{Cu}_{0.10} 0^{\square} 0.10 \mathrm{SO}_{4}$ & 0.92 & 11.00 \\
$\mathrm{Na}_{1} .80 \mathrm{Cu}_{0.10^{\circ}} 0.10 \mathrm{SO}_{4}$ & 0.87 & 10.50 \\
$\mathrm{Na} 1.61 \mathrm{Y}_{0 .} 13^{\square} 0.26 \mathrm{SO}_{4}$ & 0.44 & 6.9 \\
\hline See also Fig. 1 & &
\end{tabular}

As visible, the creation of vacancies in the solid does further enhance the rate of the surface exchange and bulk diffusion during the isotopic exchange of sodium. Investigations are in progress for using the phenomenon of hydration enhanced isotopic exchange and anhydrous sodium sulphate as a solid sorbent for simple and selective sodium 24 removal in the activation analysis of trace metals in biological matrices[5]. The special role reversible crystal hydration plays in the exchange reactivity of some minerals is also used by us for explaining neutron moderation effects and ionic migrations of fission products in minerals during the past operation of the Oklo fossilized natural nuclear reactors[6].
The contribution of Dr. Géza Tóth and Miss Júlia Zsadányi of the Institute of Isotopes of the Hungarian Academy of Sciences in the experimental part of this work is gratefully acknowledged.

\section{REFERENCES}

[1] Wah I A. C. and N. A. Bonner, 1951. Radioactivity Applied to Chemistry, J. Wiley and Sons, New York, p.37.

[2] Höfer H. H., W. Eysel and U von Alpen, 1981. J. Solid State Chem., 36: 365.

[2] Burgess J., 1978. Metal Ions in Solution, Ellis Harwood LTd. , Chichester, p.160.

[3] Lieser K. H., Ph. Götlich and I. Rosenbaum, 1984. Radiochim.Acta, 5: 38.

[5] Shreedhara Murthy R. S. and D. E. Ryan, 1982. Anal. Chim. Acta., 144: 107.

[6] The Oklo Phenomenon, Proc. IAEA CEA-Govn. of Gabon Symp. on the Oklo Phenomenon, June 23-27, 1975, Libreville, Gabon, IAEA, Vienna, 1975. 